GEOLOGICAL SURVEY CIRCULAR 531

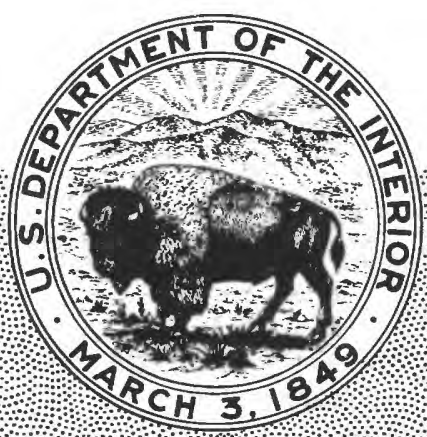

\title{
The Promise of Precise Borehole Gravimetry in Petroleum Exploration and Exploitation
}




\section{The Promise of Precise Borehole Gravimetry in Petroleum Exploration and Exploitation}

By Thane H. McCulloh

\section{GEOLOGICAL SURVEY CIRCULAR 531}

A paper presented at the Third Symposium on the Development of Petroleum Resources of Asja and the Far East, ECAFE, Tokyo, Japan, November 1965

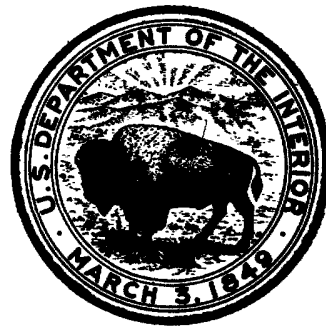


United States Department of the Interior

STEWART L. UDALL, Secretary

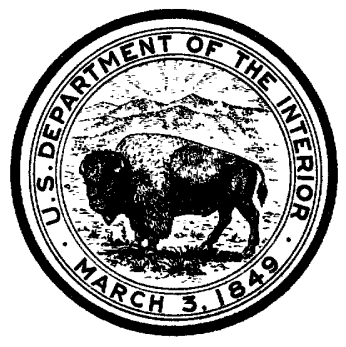

Geological Survey

William T. Pecora, Director

父

Free on application to the U.S. Geological Survey, Washington, D.C. 20242 


\section{CONTENTS}

Page

Abstract

1

Introduction. . .

Underlying physical relationships _..-- 2

Potential uses of borehole gravimetric data in petroleum exploration and exploitation ...................... 4

Determination of rock density in situ.- $\quad 4$

Uses of borehole gravimetric data

in petroleum exploration ....... 8

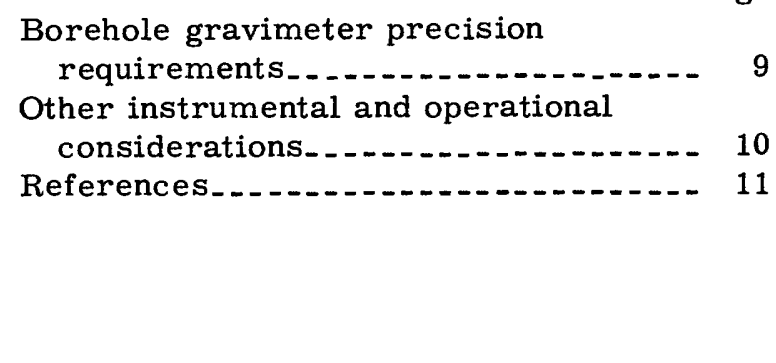

Page

(1)
10 1

(1)

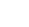

8

\section{ILLUSTRATIONS}

Figure 1. Underground (borehole) vertical gradients of gravity versus bulk rock density

2. Gravimetric effects at the axis (borehole) of cylindrical plates of unit density and thickness $\Delta Z$, as functions of different cylinder radii

3. Density in situ of fluid-saturated reservoir sandstones as functions of total porosity, different fluid compositions, and different temperatures and pressures . .

4. Borehole gravimeter precision versus precision of bulk density determinations for different values of $\Delta Z$ (vertical interval measured) 


\title{
The Promise of Precise Borehole Gravimetry in Petroleum Exploration and Exploitation
}

\author{
By Thane H. McCulloh
}

\section{ABSTRACT}

The underground vertical gravity gradient is related to rock density in situ, gravimetric effects of nonlevel surfaces of equal rock density beneath and around the borehole (including topographic effects), and the free-air vertical gravity gradient.

Accurate determinations of average rock density in situ underground could be calculated from properly interpreted precise borehole gravimeter measurements. Such determinations would be relatively free from the effects of rock damage due to drilling or invasion by mud filtrate. The measurements could be made in cased wells, and they would be based on much larger volumes of rock than are sampled by any other method. Such measurements would be independent of core-analysis data and would therefore provide a standard against which to judge the core-analysis data as well as to evaluate conclusions drawn from gamma-gamma or other logs.

Conversely, independent knowledge of rock density at a borehole would permit separation of the gravitational effects of rocks beneath and around the surveyed borehole from other effects naturally integrated in the borehole gravimeter measurements and thereby offer unique opportunities for geological exploration.

Ideally, precision of a borehole gravimeter should be \pm 0.001 milligal to permit effective use in the full variety of applications outlined in petroleum exploitation and exploration. However, an instrument having the probable presently attainable greatest precision of \pm 0.01 milligal would serve for many desirable purposes, and one having a precision of \pm 0.02 milligal would be marginally useful. Other instrumental and operational characteristics of an experimental prototype borehole gravimeter are described.

\section{INTRODUCTION}

The first underground measurements of gravity were made in England by Airy (1856) to determine the mean density of the Earth. He used pendulums to measure the vertical gradient of gravity between the top and bottom of a vertical shaft sunk through sedimentary rocks, the average density of which was estimated from laboratory measurements of bulk density of hand samples.
Many subsequent papers have been published that consider the principles, practice, instrumentation, or results of underground measurements of gravity in shafts, mines, tunnels, and boreholes. Lorenz (1938), Smith (1950), and Domzalski (1955b) are noteworthy for their contributions to the development of theory or principles; Jung (1939), Hammer (1950), Domzalski (1954), and McCulloh(1965) illustrate methods; Smith (1950), Gilbert (1952), Dolbear (1959), Lukavchenko (1962), and Goodell and Fay (1964) record instrumental considerations; and Jung (1939), Hammer (1950), Domzalski (1955b), Whetton, Myers, and Smith (1957), McLean (1961), Lukavchenko (1962), and McCulloh (1965) present particularly important observational data. Other pertinent papers are those of Rogers (1952), Miller and Innes (1953), Domzalski (1955a), Egyed (1960), Plouff (1961), Gran (1962), Hammer (1963a,b), Secor, Meyer, and Hinze (1963), and Thyssen-Bornemisza (1963, 1964).

Despite the considerable interest in the potential value of underground and borehole gravimetry manifested by this rather extensive literature and because of the technical difficulties and expense of designing and fabricating a gravimeter capable of operating with high precision in a borehole, publicized attempts have thus far met with only limited success (Gilbert, 1952; Lukavchenko, 1962; Van Melle and others, 1963, p. 475; and Goodell and Fay, 1964). In considering these difficulties and the remaining obviously for midable design problems, it is desirable to take stock of the practice and promise of precise borehole gravimetry in petroleum exploration and exploitation, with the objective of determining those instrumental objectives that now appear desirable in view of the geologic problems and those which are worth 
pursuing, considering their technical difficulty and high cost.

The author appreciates the many stimulating discussions of some aspects of this report held with Dr. L. J. B. LaCoste, Mr. J. E. Schoellhamer, Dr. R. E. von Huene, Mr. L. A. Beyer, and Mr. R. R. Clawson. Appreciation is also expressed to the Research Corp. for financial assistance granted through the University of California, Riverside, which helped stimulate work that led indirectly to this report.

\section{UNDERLYING PHYSICAL RELATIONSHIPS}

Above the ground surface, the difference in the acceleration due to gravity between two points vertically above one another may be expressed as

$$
\Delta g_{a}=F \Delta Z+\Delta C_{t}+\Delta C_{g}
$$

where $\Delta g_{a}=$ the gravity difference between two points on a vertical line in air;

$\Delta Z=$ the elevation difference between the two points;

$F=$ the free-air vertical gradient of gravity;

$\Delta C_{t}=$ the difference between the two points in the correction for surface terrain irregularities; and

$\Delta C_{g}=$ the difference between the two points in the correction for underground geology below the local datum level.

The free-airgradient varies as a function of both latitude and altitude, according to the relation (Heiskanen and Vening Meinesz, 1958 , p. 54)

$$
\Delta g=\left(0.30877-0.00044 \sin ^{2} \theta\right) Z_{m}-0.073 z_{k m}^{2}(2)
$$

where $\Delta g=$ the gravity difference in milligals between a point at sea level and another point in air vertically above the first;

$z_{m}=$ the vertical distance between the two points in meters;

$z_{k m}=$ the vertical distance between the two points in kilometers; and $\theta=$ the latitude.

However, the total latitudinal variation at sea level is small-only $0.00044 \mathrm{mgal}$ per $\mathrm{m}$ (milligal per meter) between equator and poles-and the variation from the sea-level value because of elevation is also small$0.00015 \mathrm{mgal}$ per $\mathrm{m}$ less than the sea-level value at 1,000 meters for all latitudes. Thus, it is clear that measured large departures from the so-called normal free-air vertical gradient value of $0.3086 \mathrm{mgal}$ per $\mathrm{m}$ must arise from surface terrain or subsurface geologic effects. Where the terrain is flat or where the gravitational effects of surface topographic irregularities may be calculated, only subsurface geologic irregularities remain to account for measured deviations from the normal value of $F$. This fact motivated Evjen (1936), among others, to examine the possible geologic utility of measurements or computations of the surface vertical gradient of gravity, and caused Hammer (1938), Thyssen-Bornemisza and Stackler (1956), and Kumagai, Abe, and Yoshimura (1960) to measure and analyze in various terms local departures from the normal value. Kumagai and others (1960) observed local departures of more than 10 percent from the normal value even after correction for terrain effects (fig. 1).

Beneath the ground surface, the vertical gradient of gravity is similarly a function of the free-air gradient at the particular latitude and elevation, and is similarly modified by surface topographic irregularities and subsurface geologic irregularities; in addition, it is influenced very strongly by the density of the plate of rocks between two vertically separated points of measurement, and may be significantly influence locally by the size and shape of the hole in which meas urements are made. The relationships among these variables are expressed as

$$
\Delta g_{u}=(F-4 \pi k \sigma) \Delta Z+\Delta C_{t}+\Delta C_{g}+\Delta C_{b}
$$

where $\Delta g_{u}=$ the gravity difference between two points on a vertical line underground;

$k$ = the gravitational constant;

$\sigma=$ the density of the horizontal plate of rock that separates the two points of measurement;

$\Delta C_{g}=$ the differential effect of departures from horizontality of the surfaces of equal rock density above and below the measurement interval, but below the local gravity survey elevation datum; 
$\Delta C_{b}=$ the differential gravitational ef fect of the borehole, its mud cake, its cement, its casing, and the borehole fluid density;

$\Delta C_{t}=$ the differential effect of terrain irregularities and unlevel sur faces of equal rock density above the local gravity survey elevation datum;

$\Delta Z$ = the elevation difference between the two points; and

$F=$ the free-air vertical gradient of gravity.
Clearly, if $\Delta g_{u}$ could be measured, if $F$ is known or can be reliably assumed, if $\Delta Z$ can be accurately measured, and if the terms for the differential effects of surface terrain, subsurface geology, and borehole influence are negligible or can be evaluated, equation 3 can be solved for $\sigma$, the bulk rock density in situ (Jung, 1939; Hammer, 1950; Smith, 1950). Conversely, if $\sigma$ could be accurately determined independently of gravity measurements (by core-sample analysis or by gamma-gamma logging, for example) and if accurate numerical values could be substituted

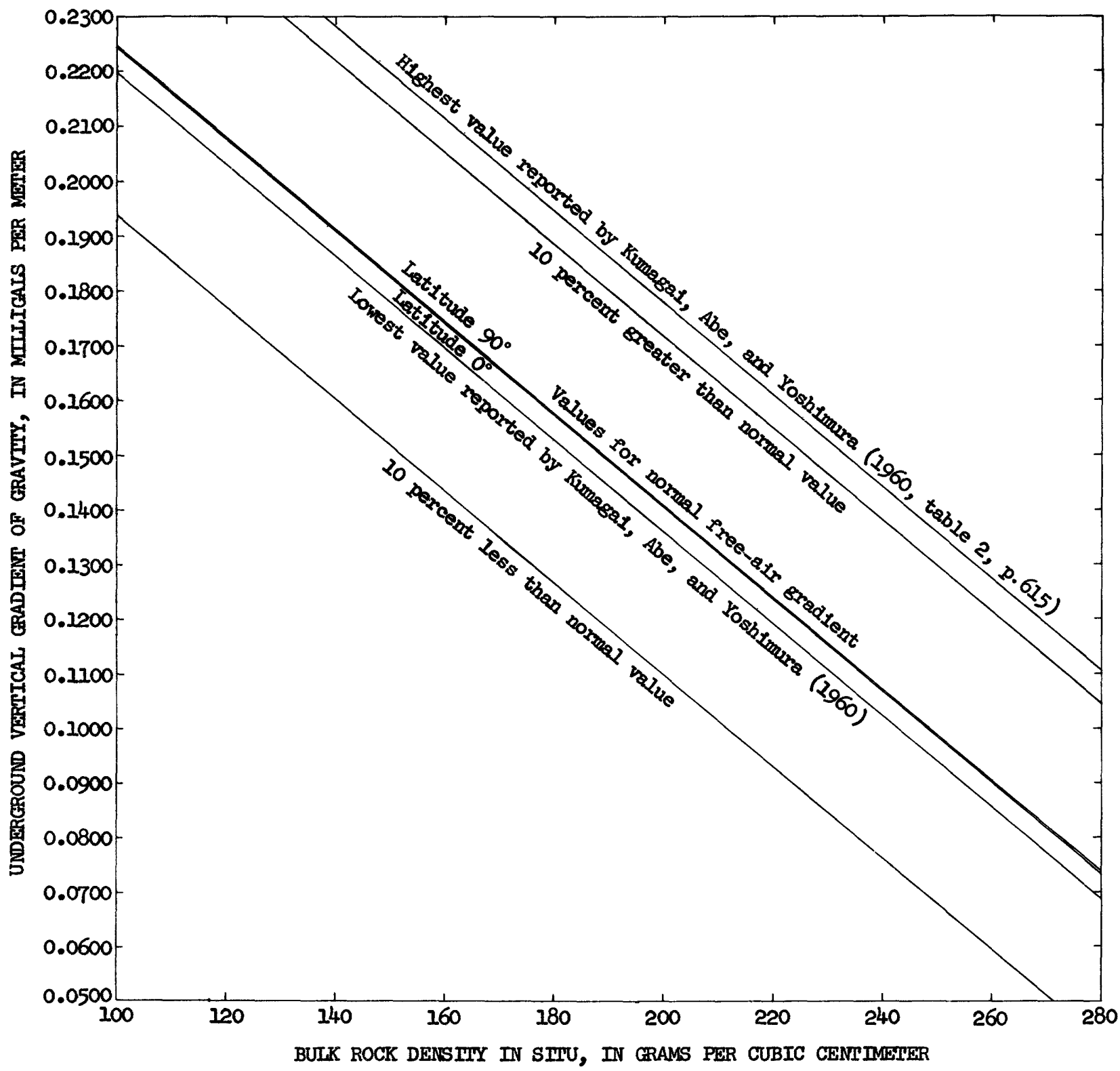

Figure 1. - Underground (borehole) vertical gradients of gravity versus bulk rock density in situ. 
for all but the $\Delta C_{g}$ term of equation 3 , the underground equivalent of the surface Bouguer gravity anomaly value could be obtained (Smith, 1950). From the standpoint of the underlying principles, therefore, borehole gravimetry has a direct bearing on questions of interest in both petroleum exploration and exploitation (as well as in other subsurface geologic investigations). Some practical consequences and requirements that emerge from consideration of these two major potential uses of borehole gravimetric data are reviewed or examined in detail below.

\section{POTENTIAL USES OF BOREHOLE GRAVIMETRIC DATA IN PETROLEUM EXPLORATION AND EXPLOITATION}

Most of the specific potential uses of borehole gravimetric data in petroleum exploration were recognized and thoroughly examined by Smith (1950). He classified the areas of application into three related but separate groups - the understanding of borehole geology, interpretation of surface gravity surveys, and interpretation of seismic data. A fourth group of applications, aids to evaluation of petroleum reservoir characteris tics and performance, can be foreseen also. Furthermore, some of the applications outlined by Smith deserve reexamination or emphasis in light of other developments since 1950 .

\section{DETERMINATION OF ROCK DENSITY IN SITU}

The greatest benefits of a precise borehole gravimeter to the technology of petroleum exploration and exploitation would probably stem from its use as a tool for measuring rock density in situ (Lorenz, 1938; Jung, 1939), because precise borehole measurements of gravity would provide accurate measurements of bulk rock density in situ, independent of core samples or of any indirect method of measurement. Equation 3 shows that the underground gradient of gravity is directly dependent on the rock density of the horizontal plate of rock between two vertically separated stations. The bulk rock density may be expressed as

$$
\sigma_{i s}=\sigma_{f} \phi+\sigma_{g}(1-\phi)
$$

where $\sigma_{i s}=$ the bulk rock density in situ; $\sigma_{f}=$ the density in situ of the porefilling fluid(s);

$$
\begin{aligned}
& \sigma_{g}=\text { the density of the mineral grains; } \\
& \text { and } \\
& \phi=\text { the porosity expressed as a } \\
& \text { fraction. }
\end{aligned}
$$

Not only is the dependence of $\Delta g_{u}$ on $\sigma_{i s}$ direct, but measurement of $\sigma_{i s}$, by borehole gravimetric methods would be in situ; thus, volume changes that might result from elas tic expansion of the rock upon depressuriza tion, exposure of the rock to the atmosphere, mechanical damage to cores during drilling, or changes in pore-fluid composition are absent or minimal. Questions of the type that perplex the interpreter of gamma-gamma logs or that should be of concern to the user of core analysis data could be circumvented by borehole-gravimeter density meas urements. Furthermore, the volume of rock effectively sampled by the borehole-gravimetric technique would be vastly larger and more representative than that sampled by any other known method of measurement. Figure 2 is a plot of the gravimetric effects of a series of cylindrical plates of thickness $\triangle C$ and unit density that are coaxial with a vertical borehole. The effects shown are expressed as percentages of the effect of an infinitely extended horizontal plate of the same thickness and density, and are plotted as a function of differing cylinder radii (expressed as multiples of their thickness). About 65 percent of the effect of an infinitely extended plate of thickness $\Delta Z$ arises from the volume of rock within a radius of the measured interval in the borehole of $1 \Delta Z$,

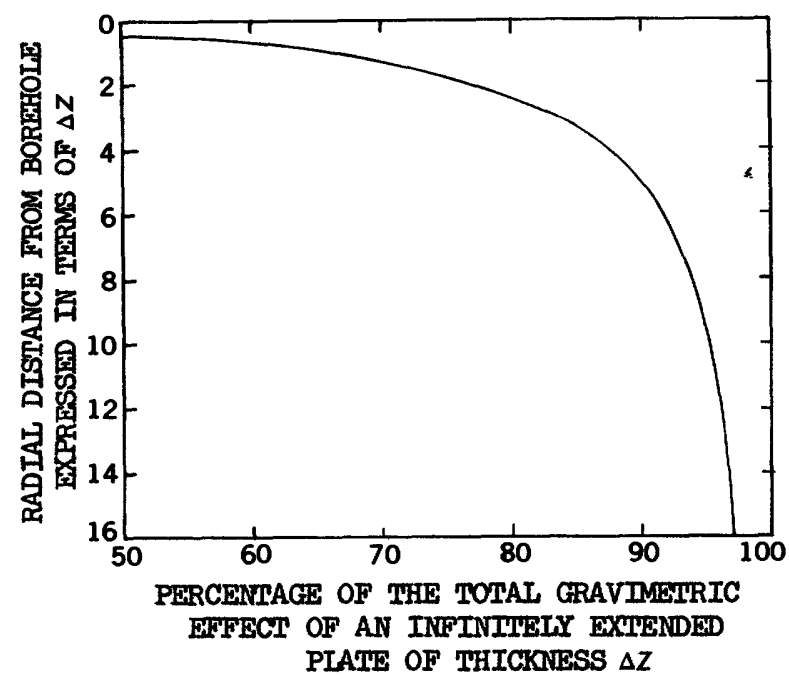

Figure 2.-Gravimetric effects at the axis (borehole) of cylindrical plates of unit density and thickness $\triangle Z$ as functions of different cylinder radii. 
and 77 percent arises from within a radius of $2 \Delta Z$. Beyond a radius of $4 \Delta Z$, the rate of increase of the gravimetric effect begins to fall off sharply, and 90 percent of the total effect occurs from within a radius of only $5 \Delta z$. In theory, by adjusting the vertical measurement interval, average -interval density values could be obtained that would represent appropriately large volumes of rock; this would avoid nearly all problems that are due to formation invasion by drilling fluid filtrate, to formation damage by the drilling process, and to difficulties in obtaining a statistically valid sample from a formation interval by conventional cores. The gravimeter precision needed to accomplish this objective over depth intervals that would be generally meaningful is thoroughly considered in later pages.

If we grant that the borehole gravimetric technique in theory offers a promising method of directly measuring the average density of relatively large samples of undisturbed rock in situ underground and set aside for the moment the extremely important question of the gravimeter precision needed for such a task, in what ways would such density measurements be useful if they could be made?

Possibly the most significant single use of precise borehole gravimetric data would be to establish detailed density profiles to serve as absolute standards for evaluating core-analysis data and procedures. All presently available methods of estimating underground rock density or porosity in detail depend either directly or indirectly on laboratory analysis of core samples (Pickell and Heacock, 1960; L. E. Schneider, oral commun., June 23, 1965). The field gravimetric studies of Hammer (1950)-revised by McCulloh (1965)-and of Whetten, Myers, and Smith (1957) and the laboratory investi gations of Fatt (1958) suggest that sedimentary rocks expand as they are cored and withdrawn, that rock damage during drilling may cause volume expansion, or both. Conversely, Domzalski (1955b), finding laboratory density measurements of hand samples of faulted and brecciated rock and of partly mineralized ore specimens to be greater than the average density calculated from underground gravity measurements in Cumberland and Surrey, England, concludes that hand samples fail to reflect properly the amount of fracture porosity and the amount of gangue in such rocks. Furthermore, the author (McCulloh, 1965) has shown that the effect of weathering of old cores is small but appreciable, even when they have been carefully stored, and that this effect also is one of volume expansion. The extent and variation of such differences between the volumes of core samples and the equivalent rock volumes in situ underground would be illuminated by comparison of gravimetrically derived density profiles and core-analysis data.

From such comparisons, analyses could also be made of errors that result from defects in laboratory procedures for measuring volume of core samples for determination of density or porosity. Under optimum conditions, the weight and bulk volume of a core sample can be measured routinely in the laboratory with accuracies such that the density of the sample can be known within $+0.005 \mathrm{~g}$ per $\mathrm{cm}^{3}$. Tests and comparisons by the author have shown that some commercial laboratory procedures in routine use yield bulk-volume measurements that may be as much as 15 percent too high for rough-surfaced specimens of high total porosity. The need for an absolute standard for comparison, evaluation, and standardization is clear; and a precise borehole gravimeter, if properly used, could provide such a standard.

Inasmuch as conclusions reached about rock density or porosity from gamma-gamma radiation logs and acoustic velocity logs depend indirectly on core-analysis data, direct comparisons between such logs and gravimetrically derived density profiles would result in better understanding and more complete and intelligent use of such indirect methods of borehole measurement of rock density. Additionally, because a gravimetric profile of rock density would be little changed by the effects of formation damage due to drilling and invasion by mud filtrate, from the differential effects of mud cake or variable thickness of mud cake, or from the effects of variable hole diameter, it would serve admirably as a basis for analyzing the relatively important effects that such variables have on a density profile obtained by gamma-gamma logging. The improvements to be expected from such comparisons in the interpretations of indirect techniques of density and porosity measurement presumably would eventually establish core-analysis and gamma-gamma log interpretations as completely reliable and trustworthy methods in 
their own right. This would, in turn, permit certain unique uses, to be described on later pages, of the $\Delta \mathrm{C}_{g}$ term of equation 3, with far-reaching consequences for petroleum exploration.

Sedimentary-rock density, and therefore porosity, has long been known from core analysis to vary systematically with depth because of gravitational consolidation during burial and loading (Athy, 1930; Hedberg, 1936). With the acquisition of more detailed density and porosity data has come a growing awareness that lithology, age, temperature, sedimentary environment, structural history, and pore-fluid pressure history play important roles in determining or modifying these properties of sedimentary rocks (Nafe and Drake, 1957; Dallmus, 1958; Lerbekmo, 1961; Meade, 1963; McCulloh, 1963; Maxwell, 1964). Establishment of a reliable and accurate method of measuring density in situ in boreholes would permit more rapid and dependable investigation of these relations and their significance in petroleum exploration and exploitation. Such investigations might clarify such fundamentally important problems as (1) maximum depth of commercially attractive reservoir rocks, (2) the relation between degree of consolidation and extent of petroleum migration and accumulation in young sedimentary materials, (3) variation with age and other factors of the sedimentary rock depth-density function, and (4) the distribution of fracture porosity or vugular porosity in otherwise massive rocks.

Because fluid density ( $\sigma_{f}$ of equation 4) constitutes an important fraction of the bulk rock density in rocks of more than a few percent porosity and because grain density varies so little among many sedimentary rocks (Davis, 1954), precise measurements of rock density in situ underground would provide a means of gaining information about the pore-fluid density in situ. Under various conditions, such information could be used to great advantage in evaluating a newly discovered potential reservoir or in monitoring the performance of a producing reservoir. As an illustration, assume that a porous zone suspected of being a potential reservoir has been drilled and cored, but mud cake and invasion of the zone by mud filtrate have made uncertain the degree of petroleum saturation in the cores and in the formation. Core and electric-log analysis will indicate the approximate average total porosity for the zone. Examination of ditch cuttings will suggest an average lithology and grain density. Sufficiently precise measurement of the vertical gradient of gravity in or through the interval-corrected for the effects of surface terrain, approximately for subsurface geology, and (if necessary) for borehole ir regularities-would permit computation of the bulk rock density in situ. Substitution of $\sigma_{i s}, \sigma_{g}$, and $\phi$ in equation 4 would then permit computation of $\sigma_{f}$. Knowing that interstitial water has a density at nearly all temperatures and pressures of $1.00 \mathrm{~g}$ per $\mathrm{cm}^{3}$ and that most natural petroleum fluids have distinctively lower densities at nearly all temperatures and pressures, as shown in figure 3 , a realistic decision could be made to test the zone (or persist in testing it) or to ignore it. Furthermore, if the zone temperature and approximate fluid pressure were known and if experience in the region led one to suspect a certain interstitial water content and a particular oil gravity in the possible oil zone, the analysis of fluid character could be made rather closely from the data specified above.

As a second illustration, take the hypothetical case of a known productive well in which it is desired to periodically monitor the performance of a producing reservoir unit. We presume that a considerable body of factual data regarding the physical properties of the reservoir unit has been gathered and is available. These data include estimates of the average total porosity, grain density, temperature, fluid pressure, tank oil gravity, and interstitial water content and salinity. The produced gas gravity and an estimate of the reservoir gas-oil ratio would also be available. From these quantities, the density of the fluids in the pore space could be calculated fairly accurately using, for example, the correlation equations of Standing (1947). Measurement of the underground vertical gradient of gravity through the producing interval (or a carefully selected part of it) could be made prior to production from the reservoir or early in its productive life by using a precise borehole gravimeter. Repeated measurements over the same interval, at time intervals dictated by the rate of production in relation to the reservoir volume, would show vertical gravity gradient changes. that would reflect only the changes in fluid density (and to a slight extent in pore volume, if diminution of reservoir volume occurs as the reservoir pressure falls). In 


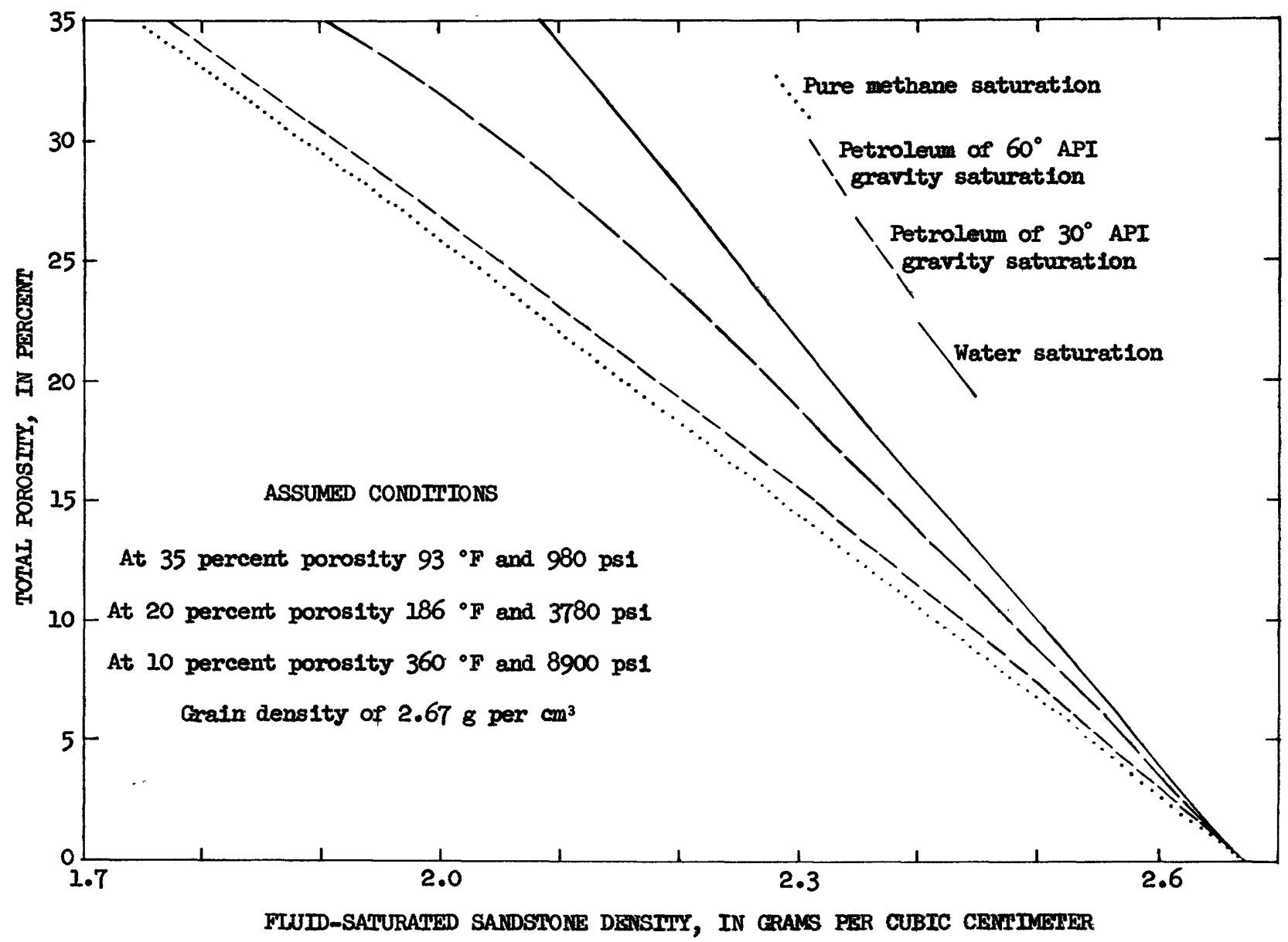

Figure 3. -Density in situ of fluid-saturated reservoir sandstones as functions of total porosity, different fluid compositions, and different temperatures and pressures.

an initially undersaturated reservoir in which gas expansion and gravity drainage dominate, and water drive is absent or of slight importance, the fluid density throughout the reservoir would decrease during production and pressure decline until a free gas-cap of very low density began to develop and expand. In an undersaturated reservoir in which an active water drive provides most of the reservoir energy, the encroachment of relatively dense water could be observed as the oil-water interface changes position. In either reservoir type, irregulari:es in the fluid behavior could be observed indirectly, and thereby possibly could be controlled through adjustment of rates of production in wells causing the irregularities.

Reservoir monitoring of the sort described above would also probably find use in water-flooding operations and in other types of secondary recovery operations. However, it is equally probable that considerable experimentation and empirical observation would be required to develop a satisfactory understanding of both the uses and the limitations of such applications.

A final statement is in order regarding the suitability of the methods described above in cased wells. Smith (1950, p. 630635 and fig. 16) has shown that factors such as casing, changes in casing size, and cement behind casing generally influence the underground vertical gradient of gravity so slightly as to be negligible. Only if the borehole gravimeter were read within four to five times the diameter of the well from the end of a casing or of a casing joint of different size would differential effects appear. Thus, the borehole gravimeter would be ideally suited to measure rock density in situ in cased wells without excessive interference from casing or cement, as long as tops and 
bottoms of casing joints of different size or of cement columns behind casing are known and avoided. This matter is referred to later in connection with consideration of borehole gravimeter precision requirements.

\section{USES OF BOREHOLE GRAVIMETRIC DATA IN PETROLEUM EXPLORATION}

Although a precise borehole gravimeter probably would at first have its greatest value as a tool for accurately measuring rock density in situ, it would be immediately useful and important as a tool for improving in several ways the interpretations of surface gravity data. Its value for subsurface gravity mapping and prospecting in extensively developed productive basins might ultimately equal (or possible even exceed) its value to logging and petroleum exploitation technology.

Smith (1950, p. 614) effectively presented strong arguments for utilizing precise borehole gravity data from shallow holes to compute reliable elevation correction factors for use in reduction of surface gravity data. This refinement of the method of Nettleton (1939) should also be accompanied by meas urements, at each site, of the free-air gradient of gravity above the ground surface, for use in calculating rock density from equation 3 and for use in reducing the surface gravity data, as suggested by Kumagai and others (1960).

Smith (1950, p. 616-617) and Hammer (1950) also make a strong case for using a borehole gravimeter to establish the depthdensity function on a more-or-less regional basis to serve as background against which to interpret local undrilled surface gravity anomalies. Neither core-analysis data nor gamma-gamma logs provide completely trustworthy bases for such conclusions, although core-analysis data have been used with surprisingly good results by the writer (McCulloh, 1960 and 1965) and gamma-gamma logs have yielded similarly interesting results (Hammer, 1963).

Other uses of precise borehole gravity measurements in petroleum exploration depend on interpretation of the $\Delta C_{g}$ term of equation 3 . We have seen that substitution of $\mathrm{F}, \sigma, \Delta \mathrm{C}_{t}$ and $\Delta \mathrm{C}_{b}$ in equation 3 would permit computation of $\Delta C_{g}$. Because $\Delta C_{g}$ is the term that arises mainly from the geology beneath and above the measurement interval in the borehole and because the strata above the interval presumably could be fairly well evaluated in terms of rock density in general, reliable computation of the $\Delta C_{g}$ term provides a measure of the effect of the unknown rocks beneath the borehole. Interpretations of such $\Delta C_{g}$ terms measured in intervals along a borehole-especially when coupled with interpretations of surface gravity data from geologic and density models based on syntheses of structural, stratigraphic, and seismic data-would provide a powerful means of extending to depth interpretations that would otherwise be meaningless because of the attenuating effect of depth on gravity anomalies of small height-to-width ratio.

Problems that would plague early efforts to interpret borehole gravity measurements in terms of the geologic correction term can be expected to diminish with application of such a tool. It is apparent that departures from level of surfaces of equal rock density beneath a surveyed well create disturbances in the free-air gradient of gravity underground as well as at and above the ground surface. Presumably, the $F$ term could be measured above the ground surface at the surveyed well site, and surface gravity maps around the well site could be used for estimating the underground variations in the $F$ term along the vertical hole (Evjen, 1936; Hammer, 1938; Henderson and Zietz, 1949). Without an understanding of the geology and density distribution for a considerable distance around and beneath the surveyed well, however, estimates of $F$ values underground could be little better than educated guesses because of uncertainties in calculated $\Delta C_{g}$ terms. Similarly, until the reliability of core-analysis data as a measure of rock density in situ has been established beyond doubt by use of a precise borehole gravimeter at sites where the $F$ term of equation 3 can be determined with high accuracy, doubt will exist about the reliability of any values of $\sigma$ substituted in equation 3 and, therefore, about the reliability of values of $\Delta \mathrm{C}_{g}$ computed from them. One of the most compelling reasons for thorough investigation of the relationship between estimates of rock density in situ by each of several methods and actual density of rocks underground arises from the foreseeable need for 
absolutely accurate values of $\sigma$ to substitute in equation 3.

Field use of a precise borehole gravimeter will result in fairly rapid clarification of the problems outlined above; and with the accumulation of observational data and experience, their consequences will diminish. It is clear that early efforts to use and interpret borehole gravity measurements would be most fruitful in extensively explored areas where much is already known about the subsurface geology. Thus a precise borehole gravimeter would be much more important in early applications to exploitation or development geology, and its contribution to purely exploratory operations might be slight at first. One exception to this statement is in regional interpretation of surface gravity maps, which would benefit extensively and quickly from density data gathered from exploratory wells.

\section{BOREHOLE GRAVIMETER PRECISION REQUIREMENTS}

The potential theoretical applications of a borehole gravimeter are as varied as they are interesting. Therefore, the precision required in an instrument to be used in any except a purely experimental program deserves reexamination in terms of each possible use.

Inasmuch as a borehole gravimeter would be used mostly to obtain measurements of the vertical gradient of gravity underground, the precision requirements are somewhat less rigid than for an instrument intended to yield absolute measurements, because a loss of precision in measurement of $\Delta g$ could be compensated in part by enlarging $\Delta Z$ to diminish the error in the ratio $\Delta g / \Delta Z$. Figure 4 is a graph of differing gravimeter precision (or alternatively, precision of $\Delta g$ ) plotted against differing precision of bulk density determinations based on the underground vertical gravity gradient for different values of $\Delta Z$. If it is desired to measure density in situ over a depth interval of 10 meters, a borehole gravimeter having a reading precision and accuracy of $\pm 0.1 \mathrm{mgal}$ will yield a determination having a precision of to.24 $g$ per $\mathrm{cm}^{3}$, and an instrument that can be read to $\pm 0.01 \mathrm{mgal}$ will yield a determination of $\pm 0.02 \overline{4} \mathrm{~g}$ per $\mathrm{cm}^{3}$ Probably a practical limit to the precision of most modern sur- face gravimeters used in prospecting is $\pm 0.005 \mathrm{mgal}$, and reproducibility of \pm 0.01 to $\pm 0.02 \mathrm{mgal}$ is probably more characteristic. Therefore, it is difficult to envision a borehole instrument having a precision better than \pm 0.01 mgal at present (1965).

On an earlier page, it was stated that the density of an individual core sample of compact sedimentary rock can be measured in the laboratory with a precision of about $\pm 0.005 \mathrm{~g}$ per $\mathrm{cm}^{3}$. However, sampling inadequacies and core volume changes, together with measurement errors, created a discrepancy of minus $0.013 \mathrm{~g}$ per $\mathrm{cm}^{3}$ when a core sample density profile was compared with a profile based on gravity measurements in a 2,500-foot mine shaft through Paleozoic rocks (McCulloh, 1965). If the precision of core sample determinations thus ranges in practice from \pm 0.007 to about $\pm 0.013 \mathrm{~g}$ per $\mathrm{cm}^{3}$, depending on the amount of effort spent to overcome sampling inadequacies, a borehole gravimeter having a precision of \pm 0.01 mgal could give an average value of equivalent or better precision over a depth interval of about 50 meters. Moreover, the gravimetric average value would be based on an almost infinitely larger sample in situ and mainly undisturbed. Obviously, for establishment of calibration standards or for gathering density and porosity data for any one of the varied applications outlined above, an instrument of this sensitivity would be extremely useful.

A borehole gravimeter having a precision and accuracy of $\pm 0.01 \mathrm{mgal}$ would probably be marginally useful as a device for monitoring the fluid-density changes in most producing reservoirs, but it would be of very great importance in the evaluation of fluid content of newly discovered reservoirs. The densities of reservoir rocks saturated with petroleum fluids differ from the densites of the same rocks saturated with water by 0.35 to $0.01 \mathrm{~g}$ per $\mathrm{cm}^{3}$. For reservoir units 10 to 100 meters thick, such density differences would produce discernible effects in the underground vertical gravity gradient, but changes in densities that would occur during production of such a reservoir might or might not be detectable. The gravity gradient would obviously be affected by expected changes in fluid density in a larger vertical petroleum column. 
Smith (1950, p. 618) concluded that for many subsurface exploratory applications a borehole gravimeter precision of $\pm 0.2 \mathrm{mgal}$ would suffice. This conclusion has been justifiably questioned (Dolbear, 1959), but a precision 10 times as great, $t 0.02 \mathrm{mgal}$, would certainly provide an instrumental capability of broad value to petroleum exploration. Even greater precision would not be wasted, whereas an instrument much less sensitive than $+0.02 \mathrm{mgal}$ would appear to have limited practical value. Inspection of figure 4 suggests that an almost ideal instrument ought to have a precision of \pm 0.001 mgal. Density differences greater than $\pm 0.003 \mathrm{~g}$ per $\mathrm{cm}^{3}$ could then be readily detected in thickness intervals of only $10 \mathrm{me}-$ ters. Such an instrument (or its equivalent, a vertical gravity gradiometer having a sensitivity of $\pm 0.0002 \mathrm{mgal}$ per $\mathrm{m}$ ) would be fully sensitive enough to provide data of great usefulness in each of the applications discussed here and by Smith (1950). In particular, it would permit a very substantial increase over any other method in the accuracy with which rock density can be measured.

\section{OTHER INSTRUMENTAL AND OPERATIONAL CONSIDERATIONS}

Dolbear (1959) has given a rather complete review of the dimensional and other design characteristics desirable in a practical borehole gravimeter, and nothing need be added to his statements regarding these considerations. However, emphasis should be placed on the word "practical," in order to call attention to the fact that an experimental prototype need not have all the characteristics of a final instrument suitable for routine industrial applications. An instrument could be operated in enough places and depths to provide an ample test of the usefulness of the method if it had a sensitivity of t0.01 mgal, a worldwide range, a temperature tolerance of $100^{\circ} \mathrm{C}$, a diameter of about 14.0 centimeters ( 5.51 in.) to fit inside a pressure vessel having an outside diameter of about 16.5 centimeters, and the capability of withstanding fluid pressures of 8,000 pounds per square inch and if it could be leveled inside a cased borehole inclined $7 \frac{1}{2}{ }^{\circ}$ from vertical. Moreover, it would be a vehicle for establishing the exceedingly

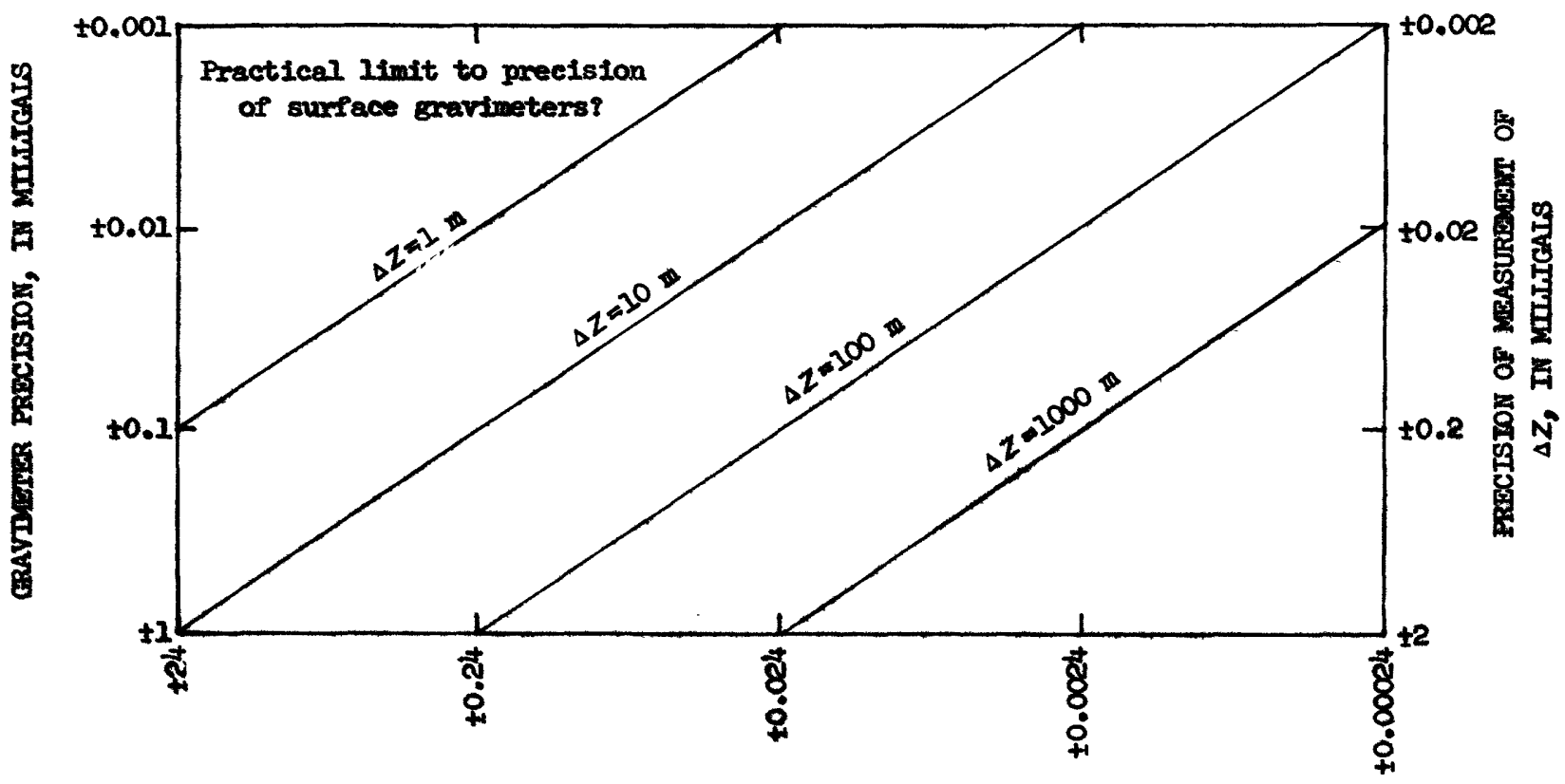

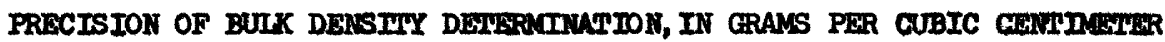

Figure 4. -Borehole gravimeter precision versus precision of bulk density determinations for different values of $\Delta Z$ (lnterval thickenes). 
important basis for comparison of gravimetric density profiles with core-analysis and gamma-gamma logging data, particularly in soft, highly porous clastic rocks where presently available methods of density meas urement are least reliable. Lastly, it would provide an experimental and empirical basis for future decisions about more compact instruments of higher temperature tolerance better suited to routine industrial uses. Such a prototype instrument appears to be both technically and economically within reach (Dr. Lucien J. B. LaCoste, oral commun., July 16, 1965).

\section{REFERENCES}

Airy, G. B., 1856, Account of pendulum experiments undertaken in the Harton Colliery for the purpose of determining the mean density of the earth: Royal Soc. Philos. Trans., v. 146, nos. 14 and 15, p. 297-342 and p. 343-355.

Athy, L. F., 1930, Density, porosity, and compaction of sedimentary rocks: Am. Assoc. Petroleum Geologists Bull., v. 14, no. 1, p. 1-24.

Dallmus, K. F., 1958, Mechanics of basin evolution and its relation to the habitat of oil in the basin, in Weeks, L. G., ed., Habitat of oil-a symposium: Tulsa, Okla., Am. Assoc. Petroleum Geologists, p. 883931.

Davis, D. H., 1954, Estimating porosity of sedimentary rocks from bulk density: Jour. Geology, v. 62, no. 1, p. 102-107.

Dolbear, D. W. N., 1959, Design considerations of a borehole gravimeter: Geophys. Prospecting, v. 7, no. 2, p. 196-201.

Domzalski, W., 1954, Gravity measurements in a vertical shaft: Inst. Mining Metallurgy Trans., Bull. 571, v. 63, p. $429-445$.

1955a, Three dimensional gravity survey: Geophys. Prospecting, v. 3, no. 1, p. 15-55.

1955b, Relative determination of the density of surface rocks and the mean density of the earth from vertical gravity measurements: Geophys. Prospecting, v. 3, no. 3, p. 212-227.

Egyed, Lazlo, 1960, Zur Frage der Schweremessungen in Bohrlöchern: Freiburger Forschungshefte C 81, Geophysik, p. 167170.

Evjen, H. M., 1936, The place of the vertical gradient in gravitational interpretations: Geophysics, v. 1, no. 1, p. 127-137.
Fatt, Irving, 1958, Compressibility of sandstones at low to moderate pressures: Am. Assoc. Petroleum Geologists Bull., v. 42, no. 8, p. 1924-1957.

Gilbert, R. L. G., 1952, Gravity observations in a borehole: Nature, v. 170 , no. 4523 , p. 424-425.

Goodell, R. R., and Fay, C. H., 1964, Borehole gravity meter and its application: Geophysics, v, 29, no. 5, p. 774-782.

Gran, B. V., 1962, K teorii vertikal'nykh krutil'nykh vesov [On the theory of vertical torsion balances]: Leningrad. Univ. Uchenyye Zapiski, Voprosy Geofiziki, no. 303 , p. 278-287.

Hammer, Sigmund, 1938, Investigation of the vertical gradient of gravity: Am. Geophys. Union Trans., 19th Ann. Mtg., pt. 1, p. 72-82.

1950, Density determinations by underground gravity measurements: Geophysics, v. 15 , no. 4 , p. $637-652$.

-1963a, Deep gravity interpretation by stripping: Geophysics, v. 28, no. 3, p. $369-378$.

$-1963 \mathrm{~b}$, Rock densities and the vertical gradient of gravity in the earth's crust: Jour. Geophys. Research, v. 68, no. 2, p. 603-604.

Hedberg, H. D., 1936, Gravitational compaction of clays and shales: Am. Jour. Sci., 5th ser., v. 31, no. 184, p. 241-287. Heiskanen, W. A., and Vening Meinesz, F. A., 1958, The Earth and its gravity field: New York, McGraw-Hill Book Co., Inc., $470 \mathrm{p}$.

Henderson, R. G., and Zietz, Isidore, 1949 , The upward continuation of anomalies in total magnetic intensity fields: Geophysics, v. 14 , no. 4 , p. 517-535.

Jung, Heinrich, 1939, Dichtebestimmung im anstehenden Gestein durch Messung der Schwerebeschleunigung in verschiedenen Tiefen unter Tage: Zeitschr. Geophysik. v. 15 , p. $56-65$.

Kumagai, N., Abe, E., and Yoshimura, Y., 1960, Measurement of vertical gradient of gravity and its significance: Boll. Geofisica, v. 2, no. 8, p. 607-630.

Lerbekmo, J. F., 1961, Porosity reduction in Cretaceous sandstones of Alberta: Alberta Soc. Petroleum Geologist Jour., v. 9, no. 6, p. 192-199.

Lorenz, H., 1938, Beiträge zur Theorie des Erdaufbaus: Zeitschr. Geophysik, v. 14, p. 142-152. 
Lukavchenko, P. I., 1962, Nablyudeniya s gravimetrami $\mathrm{v}$ burovykh skvazhinakh i shakhtakh [Observations with gravimeters in wells and mine shafts]: Razvedochnaya i Promyslovaya Geofizika, no. 43, p. 52-64.

Maxwell, J. C., 1964, Influence of depth, temperature, and geologic age on porosity of quartzose sandstone: Am. Assoc. Petroleum Geologists Bull., v. 48, no. 5, p. 697-709.

McCulloh, T. H., 1960, Gravity variations and the geology of the Los Angeles basin of California, in Synopsis of geologic results: U.S. Geol. Survey Prof. Paper 400-B, p. B320-B325.

1963, Factors controlling subsurface density variations in post-Oligocene sedimentary rocks [abs.]: Geol. Soc. America Spec. Paper 76, p. 112.

-1965, A confirmation by gravity meas urements of an underground density profile based on core densities: Geophysics, v. 30, no. 6, p. 1108-1132.

McLean, A. C., 1961, Density measurements of rocks in Southwest Scotland: Royal Soc. Edinburgh Proc., sec. B., v. 68, pt. 2, p. 103-111.

Meade, R. H., 1963, Factors influencing the pore volume of fine-grained sediments under low-to-moderate overburden loads: Sedimentology, v. 2, no. 3, p. 235-242.

Miller, A. H., and Innes, M. J. S., 1953, Application of gravimeter observations to the determination of the mean density of the earth and of rock densities in mines: Dominion Observatory Ottawa Pubs., v. 16, no. 4, p. 3-17.

Nafe, J. E., and Drake, C. L., 1957, Variation with depth in shallow and deep water marine sediments of porosity, density and the velocities of compressional and shear waves: Geophysics, v. 22, no. 3, p. 523552 .

Nettleton, L. L., 1939, Determination of density for reduction of gravimeter observations: Geophysics, v. 4, no. 3.
Pickell, J. J., and Heacock, J. G., 1960, Density logging: Geophysics, v. 25, no. 4, p. 891-904.

Plouff, Donald, 1961, Gravity profile along Roberts Tunnel, Colorado, in Short papers in the geologic and hydrologic sciences: U.S. Geol. Survey Prof. Paper 424-C, p. C263-C265.

Rogers, G. R., 1952, Subsurface gravity measurements: Geophysics, v. 17, no. 2, p. 365-377.

Secor, G. B., Meyer, H. J., and Hinze, W. J., 1963, A density determination by underground gravity measurements in Michigan: Geophysics, v. 28, no. 4, p. 663-664.

Smith, N. J., 1950, The case for gravity data from boreholes: Geophysics, v. 15, no. 4, p. 605-636.

Standing, M. B., 1947, A general pressurevolume-temperature correlation for mixtures of California oils and greases: Oil and Gas Jour., v. 46, no. 2, p. 95-101.

Thyssen-Bornemisza, Stephen, and Stackler, W. F., 1956, Observing vertical gravity gradient: Geophysics, v. 21, no. 3, p. 771779.

Thyssen-Bornemisza, Stephen, 1963, The vertical gravity gradient in borehole exploration: Geophysics, v. 28, no. 6, p. 1072-1073.

-1964, Determination of Bouguer density in shallow holes: Geophysics, v. 29, no. 3, p. $445-446$.

Van Melle, F. A., Faass, D. L., Kaufman,S., Postma, G. W., and Seriff, A. J., 1963, Geophysical research and progress in exploration: Geophysics, v. 28, no. 3, p. 466-478.

Whetten, J. T., Myers, J. O., and Smith, R., 1957, Correlations of rock density determinations for gravity survey interpretation: Geophys. Prospecting, v. 5, no. 1, p. 20-43. 